\title{
An Economic Alternative to Bottle Trap
}

\author{
Vikas Kamble ${ }^{1}$, Dr. G. A. Hinge ${ }^{2}$ \\ ${ }^{I}$ ME Civil (Construction Management) Second year Student, Civil Engg. Dept., TSSM's Bhivarabai Sawant \\ College of Engineering \& Research, Narhe, Pune, India. \\ ${ }^{2}$ Vice Principal \& Professor, Civil Engg. Dept., TSSM's Bhivarabai Sawant College of Engineering \& \\ Research, Narhe, Pune,India.
}

\begin{abstract}
Bottle trap is an essential element in sanitary plumbing system. It is installed under wash basin or kitchen sink to drain out sullage \& trap the entry of coarser waste material into drainage system (which may lead to choking) \& also traps entry of foul gases from drainage into the house. The objective of this research is to design an innovative, hydraulically efficient \& economical bottle trap to overcome the problem of loss of trap seal due to evaporation \& to avoid choke of pipe between bottle trap \& floor trap in the bathroom. Use of elbow bend pipe with increased depth \& net cap are the new findings of this research which helps to achieve the objective. Evaporation test is carried out between existing \& new designed bottle trap to observe the better performance. New designed bottle trap is implemented under the wash basin \& analysis of discharge of water through bottle trap after every 7 days till 60 days is done. The discharge is observed to be reduced after every interval of 7 days. It is concluded to clean and rinse the bottle trap from bottom section after 2 weeks or 15 days.
\end{abstract}

Keywords: Bottle trap, Evaporation test, Foul gases, Net cap, Trap seal.

\section{Introduction}

Bottle trap is a device which is placed under wash basin \& kitchen sink that keeps our house hygienic \& clean. It traps the entry of bad smell, gases \& pest which may cause harm to our health. Bottle traps are generally manufactured in $32 \mathrm{~mm} / 40 \mathrm{~mm}$ diameter size and it has water-seal of about $75 \mathrm{~mm}$ to $90 \mathrm{~mm}$. The waste water flows from wash basin to the bottle trap \& forces the existing water in it to flow out towards drain \& is replaced by existing water. Thus, the trap-seal always remains with certain amount of water.

Bottle trap can be cleaned easily, by simply unscrew the bottom section from the main body and rinse or wash and then screw the bottom part back into place. Bottle traps are available in market in variety of materials such as, chromium plated, steel, brass, PVC etc. Now a day, bottle trap is considered as a part of home decor. Bottle trap is generally used when the plumbing space is limited in the kitchens \& bathrooms.

The bottle trap should posses adequate water seal all the time. It should be of non absorbent material. The internal \& external surfaces of the bottle trap should have smooth finish so that dirt etc does not stick to it. It requires very less space as compared to p-trap. The bottle trap is found to trap the coarser waste successfully. But it is observed that the fine waste material still passing through the trap \& get collected in the downstream pipe system.

1) To study domestic plumbing system.

\section{Objectives}

2) To investigate working of bottle trap.

3) To design an Innovative, Hydraulically Efficient \& Economical Bottle Trap.

4) To fabricate \& test designed bottle trap.

5) To convert the model bottle trap into a finished product.

\section{Methodology}

Bottle trap is suitable for all types of system of plumbing such as one-pipe system, two-pipe system, single-stack system \& single-stack partially ventilated system. The process of making of new design model begins with the use of elbow pipe. It is preferred because it has natural depth of $15 \mathrm{~mm}$ in its shape. This elbow pipe is fixed in a simple plastic bottle trap and it was observed that only a single elbow pipe can satisfy the working of bottle trap. But due to its short depth i.e. $15 \mathrm{~mm}$, there was a problem of loss of trap seal due to evaporation. To stop this problem the depth of elbow pipe is increased from $15 \mathrm{~mm}$ to $75 \mathrm{~mm}$. The water-seal of bottle trap is $90 \mathrm{~mm}$ deep. Due to which the increased depth of elbow pipe to $75 \mathrm{~mm}$ was perfect.

The sullage which is discharged through wash basin passes through bottle trap \& from bottle trap to the half inch pipe which connects the floor trap in the bathroom \& finally ends meeting the drainage. This half inch pipe between bottle trap \& floor trap chokes up and get blocked due to constant passing of sullage. To overcome 
this problem, net cap is applied under the increased depth of elbow pipe. This will help to stick the sullage discharged from wash basin in bottle trap itself. Due to this, the half inch pipe between bottle trap \& floor trap will never be able to get choked or blocked. Latter on the collected sullage can be removed from bottom section of bottle trap.

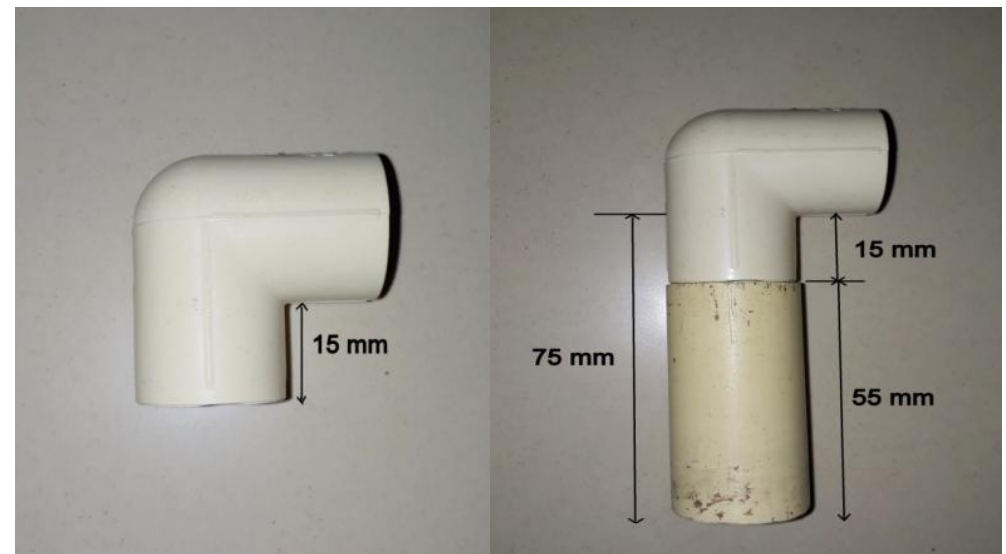

Fig1: Elbow pipe

Fig 2: Increased depth of elbow pipe

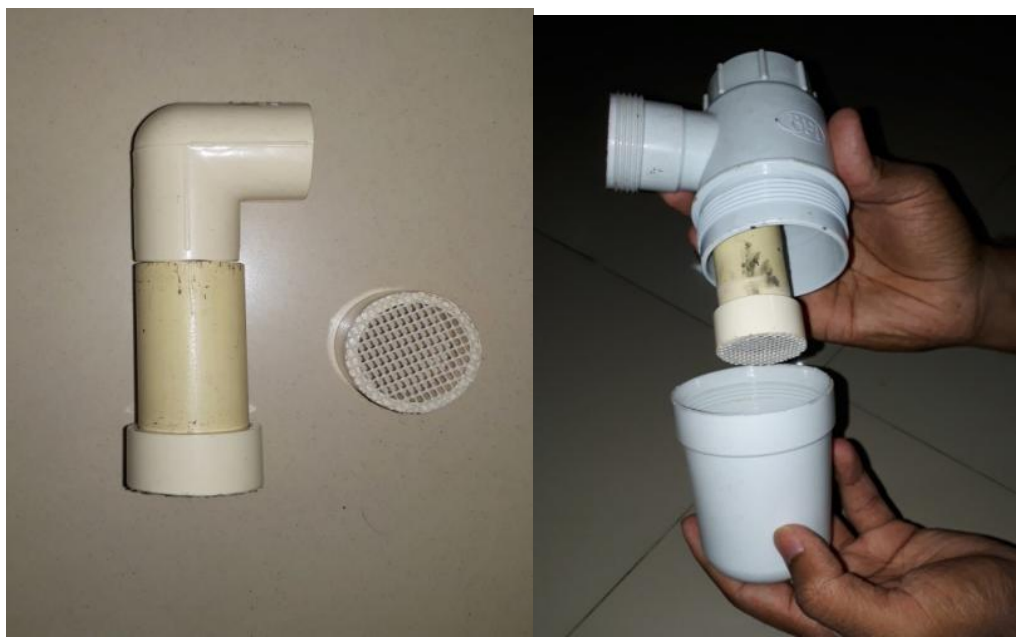

Fig 3: Net cap

Fig 4: Completed new design model

\section{Analysis}

The evaporation test is carried out to check whether the new designed bottle trap is effective over the existing old bottle trap in terms of loss of trap seal due to evaporation. Both the bottle traps are kept under sunlight with the trap seal filled with water. After 60 minutes it was observed that, water level of both the traps was equally reduced but the existing old bottle trap has lost the trap seal. Due to increased depth in new design bottle trap the trap seal was not lost even though the water level was reduced.

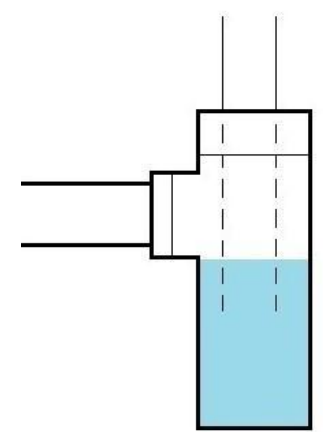

(a) Existing BT

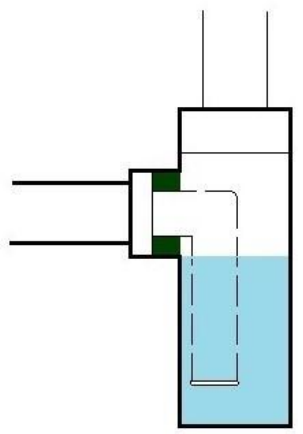

(b) New design BT

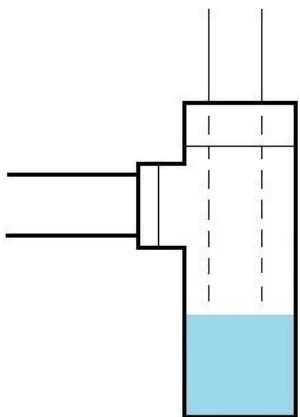

(a) Existing BT

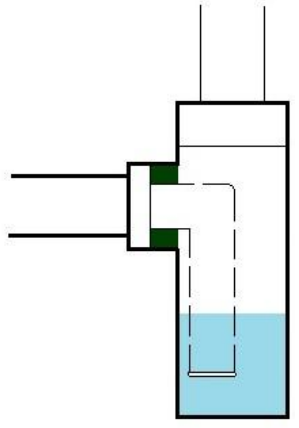

(b) New design BT

Fig 5: Before evaporation test

Fig 6: After evaporation test 
This new designed bottle trap was implemented under the wash basin \& the immediate discharge from bottle trap was calculated as;

Discharge $=$ Volume $/$ Time

$$
\begin{aligned}
& =1 \text { liter } / 21 \mathrm{sec} \\
& =0.001 / 21 \\
& =0.0476 \mathrm{lit} / \mathrm{sec} \\
& =47.6 \mathrm{ml} / \mathrm{sec}
\end{aligned}
$$

After the interval of 7 days, again the discharge was calculated as;

Discharge $=1$ liter $/ 21.5 \mathrm{sec}$

$$
=46.5 \mathrm{ml} / \mathrm{sec}
$$

After the interval of 14 days, again the discharge was calculated as;

Discharge $=1$ liter $/ 22.5 \mathrm{sec}$

$$
=44.5 \mathrm{ml} / \mathrm{sec}
$$

After the interval of 21 days, again the discharge was calculated as;

Discharge $=1$ liter $/ 24 \mathrm{sec}$

$$
=41.6 \mathrm{ml} / \mathrm{sec}
$$

After the interval of 28 days, again the discharge was calculated as;

Discharge $=1$ liter $/ 25.5 \mathrm{sec}$

$$
=39.2 \mathrm{ml} / \mathrm{sec}
$$

After the interval of 35 days, again the discharge was calculated as;

Discharge $=1$ liter $/ 26.5 \mathrm{sec}$

$$
=37.7 \mathrm{ml} / \mathrm{sec}
$$

After the interval of 42 days, again the discharge was calculated as;

Discharge $=1$ liter $/ 28 \mathrm{sec}$

\begin{tabular}{|c|c|c|c|}
\hline Day & Time (sec) & Discharge & $(\mathrm{ml} / \mathrm{sec})$ \\
\hline 1 & 21 & 47.6 & \\
\hline 7 & 21.5 & 46.5 & \\
\hline 14 & 22.5 & 44.5 & \\
\hline 21 & 24 & 41.6 & \\
\hline 28 & 25.5 & 39.2 & \\
\hline 35 & 26.5 & 37.7 & \\
\hline 42 & 28 & 35.7 & \\
\hline 49 & 29.5 & 33.8 & \\
\hline 56 & 31 & 32.2 & \\
\hline
\end{tabular}

$$
=35.7 \mathrm{ml} / \mathrm{sec}
$$

After the interval of 49 days, again the discharge was calculated as;

Discharge $=1$ liter $/ 29.5 \mathrm{sec}$

$$
=33.8 \mathrm{ml} / \mathrm{sec}
$$

After the interval of 56 days, again the discharge was calculated as;

Discharge $=1$ liter $/ 31 \mathrm{sec}$

$$
=32.2 \mathrm{ml} / \mathrm{sec}
$$

Table 1: Calculated discharge each week

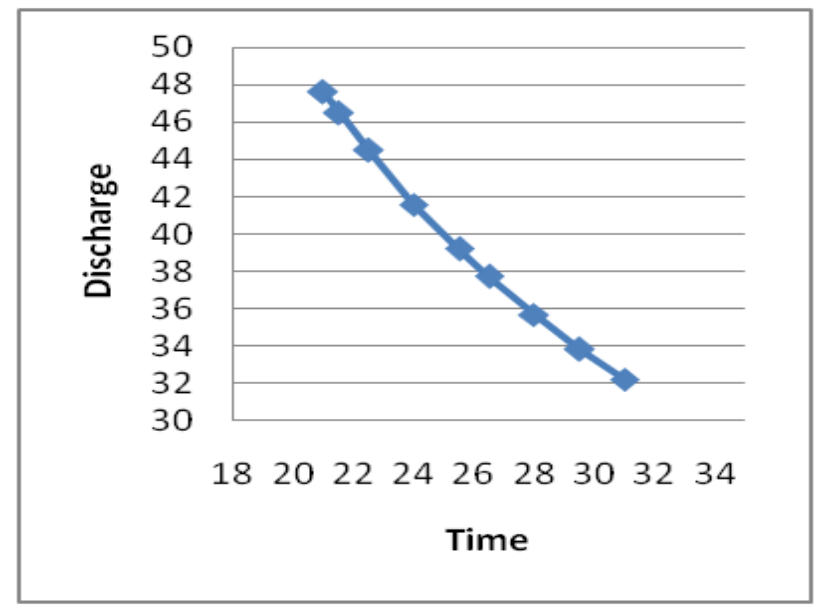

Fig 7: Time vs. Discharge 


\section{Result}

For the smooth flow of water through bottle trap without much obstruction due to sullage it is necessary to wash $\&$ rinse bottle trap after at least 15 days.

\section{Conclusion}

Thus, the hydraulically efficient bottle trap's model was made to overcome the problem of loss of trap seal due to evaporation \& to avoid choking of pipe. The evaporation test was carried out successfully; hence the better performance of new design bottle trap over existing old bottle trap was proved. The decreasing graph of discharge after every interval of 7 days shows the certain amounts of sullage gathered or stick to the net cap in the bottle trap. So, finally it is concluded to wash \& rinse the bottle trap from bottom section after at least 15 days. This will definitely prevent the choking of any further component of drainage system. The bottle trap available in the market costs around ₹600 which is thrice the cost of new design bottle trap. Thus the new designed authors bottle trap is economical than bottle trap available in the market.

\section{Acknowledgements}

I would like to express my deep sense of gratitude to my project guide Prof. Dr. G. A. Hinge for inspiring and motivating to persue the project in this field. I am deeply indebted to him for giving me this chance to study this subject and providing constant guidance throughout this work. Without his help, consistent encouragement and suggestions, the project would not have taken this form. I am grateful to the staff of Civil Engineering Department for all the help and moral support throughout the project work. Not to forget my colleagues and my parents who have gave me valuable suggestions during the work of my project.

\section{References}

[1] Subhash M. Patil (2014). Building Services (Electro-Mechanical and Environmental Services). Goregaon (E), Mumbai- 400065 : B.Prints Fort, Mumbai-400001

[2] Birdie, G. S., and Birdie, J. S. (1992). Water supply and sanitary engineering. Dhanpat Rai, New Delhi.

[3] Garg, S. K., and Garg, R. (1996). Sewerage disposal and air pollution engineering: environmental engineering (vol. 11). Khanna Publishers, Delhi-110006.

[4] P.Venkateswara Rao (2005). ENVIROMENTAL ENGINEERING (For the Course of Water Supply and Sanitary Engineering). Andhra Pradesh, Hyderabad : The Telugu Akademi, Hyderabad.

[5] Kelly, D. A., Swaffield, J. A., Jack, L. B., Campbell, D. P., and Gormley,M. (2008). "Pressure transient identification of depleted appliance trap seals: A pressure pulse technique.” Build. Serv. Eng. Res. Technol., 29(2), 165-181.

[6] McDougall, J. A., and Swaffield, J. A. (2000). "Simulation of building drainage system operation under water conservation design criteria.” Build. Serv. Eng. Res. Technol., 21(1), 41-51.

[7] Swaffield, J. A. (1996). “Simulation of building drainage flows, waste solid transport and vent system transients.” Build. Serv. Eng. Res. Technol.,17(2), B4-B8.

[8] Swaffield, J. A. (2006). "Sealed building drainage and vent systems-An application of active air pressure transient control and suppression." Build. Environ., 41(10), 1435-1446.

[9] Swaffield, J. A., and Campbell, D. P. (1995). "The simulation of air pressure propagation in building drainage and vent systems." Build. Environ., 30(1), 115-127. 